\title{
VIII. The beta-ray emission from thin films of the elements exposed to Röntgen rays
}

\section{Lewis Simons B.Sc.}

To cite this article: Lewis Simons B.Sc. (1921) VIII. The beta-ray emission from thin films of the elements exposed to Röntgen rays , Philosophical Magazine Series 6, 41:241, 120-140, DOI: 10.1080/14786442108636202

To link to this article: http://dx.doi.org/10.1080/14786442108636202

曲 Published online: 08 Apr 2009.

Submit your article to this journal $\sqsubset \pi$

Џll Article views: 2

Q View related articles $\square$

Citing articles: 2 View citing articles 5 
The case for and against the ring electron has been presented in a discussion held at a meeting of the Physical Society on October 25, $1918^{*}$.

\section{Summary and Conclusion.}

A proof is given of a theorem due to S. B. McLaren, according to which the angular momentum of a magneton of any shape or dimensions about its axis of symmetry is $\mathrm{N}_{m} \mathrm{~N}_{e} / 2 \pi$, where $\mathrm{N}_{e}$ is the number of tubes of electric induction terminating on the surface, and $\mathrm{N}_{m}$ is the number of tubes of magnetic induction passing through the aperture. Combining this result with J. W. Nicholson's natural unit of angular momentum, $h / 2 \pi$, where $h$ is Planck's constant, we find that $h$ is equal to the product of the number of tubes of magnetic induction and the number of tubes of electric induction, or $\mathrm{N}_{n}=h / \epsilon$, where $\epsilon$ is the electron charge.

A furtber relation between $h$ and $\epsilon$ is given by Lewis and Adams. This leads to a simple expression for the selfinductance of the ring, which may be combined with Lord Rayleigh's formula for the inductance of an anchor ring of circular cross-section. By employing Webster's expression for the mass of the Parson magneton and A. H. Compton's estimate for the radius of the ring, it is possible to calculate the most important numerical constants for the ring electron. A table of these constants is given, from which it appears that intense local magnetic fields must exist in the neighbourhood of the magneton.

VIII. The Beta-Ray Emission from Thin Films of the Elements exposed to Röntgen Rays $\dagger$. By Lewis Simons, B.Sc.(London), Senior Lecturer in Physics in the University of Cape Town $\ddagger$.

[Plate III.]

\section{Introductory.}

7 THE emission of corpuscles from metal plates exposed to Röntgen rays has been studied by Sadler $\S$ and Beatty $\|$. Whiddington of coupled the results of these observers with his own and showed that the maximum range, in air, of the

* Proc. Phys. Soc. vol. xxxi. pp. 49-68 (1919).

+ The expenses of this research are partly covered by a Government grant through the Research Committee of the Advisory Board of Science and Industries of the Union of South Africa.

$\ddagger$ Communicated by Prof. O. W. Richardson, F.R.S.

\$ Phil. Mag. ser. 6, vol. xix. p. 337 (1910).

$\|$ Phil. Mag. vol. xx. p. 320 (1910).

7 Proc. Roy. Soc. A. vol. Ixxxyi. p. 370 (1912). 
corpuscles varied as the fourth power of the velocity with which they emerged from the metal.

In the later work of Barkla and Shearer *, reference was made to the façt that the electrons emitted from metal plates had different associations according to whether the $\mathrm{X}$-radiation to which the plate was exposed caused it to emit the $\mathrm{K}, \mathrm{L}$, M, etc. series, or only the L, M, etc. series of tertiary $\mathrm{X}$-radiations. This would depend primarily upon the relationship between the wave-length of the exciting radiation and that of the $\mathrm{K}, \mathrm{L}, \mathrm{M}$, etc. emission lines in the radiation of the screen $\dagger$ acted upon. In spite of the different associations, it was found that the maximum velocity of emergence did not depend upon the type of X-radiation set up in the screen, the controlling factor being the wavelength of the incident X-rays; nevertheless, the authors significantly remarked that "although the exact shape of the curve depended upon the substance of the screen, the pressure at which the curve became straight was identical for all screens exposed to a particular radiation" $\ddagger$.

The work of Moseley and others on the X-ray spectra of the elements has shown the subject to be of greater complexity. There must be a distinct $\beta$-ray emission corresponding to each of the X-ray spectral lines of a given element. Interest lies in the study, not only of the maximum speed of emission, but also of any real sub-speeds that may exist (such sub-speeds not arising from any diminution in energy through the electrons having emerged from deep layers of material).

There is supporting evidence for the existence of a $\beta$-ray "spectrum" from the non-radioactive elements. Hahn $\$$ produced some interesting photographs of the $\beta$-ray "spectrum" from a thin film of radiogetive matter. Reference has already been made to the statement of Barkla and Shearer that their absorption-curves varied slightly in shape along their curved portions. $\quad 0$. W. Richardson $\|$ pointed out that

* Phil. Mag. ser. 6, vol. xxx. p. 745 (1915).

+ The elements emitting the electrons will be referred to throughout as "the screens."

$\$$ Ibid. p. 748. The curves referred to are those connecting pressure and ionization in a flat ionization chamber backed with the various screens. The ionization is due to the effect of the $\beta$-rnys from the screens upon the gas in the chamber. The pressure at which the curve becomes straight measures the range and therefore the fourth power of the velocity of the particles.

$\S$ Reproduced in Rutherford's 'Radivactive Substances and their Radiations (1913), figs. $70 \mathrm{~A}$ and $\mathrm{B}$.

|| Proc. Roy. Soc. A. vol. xciv. p. 272 (1918). 


\section{$122 \mathrm{Mr}$. L. Simons on the Beta-Ray Emission from}

the paths of the electrons emerging from the gaseous atoms, shown in (I. T. R. Wilson's cloud experiments, do not vary continuously from a maximum downwards, whilst to be completely satisfied, the photo-electric equation requires that each $X$-ray spectral line shall be accompanied by a corresponding $\beta$-ray spectral line.

The X-ray spectrum of an element is invariable except in that the lines of shorter wave-length may be entirely absent if the incident waves are of longer wave-length; on the contrary, the $\beta$-ray spectrum will vary completely with the wave-length of the incident radiation. Assuming that the photo-electric equation does apply, we have

$$
\frac{1}{2} m v^{2}=h v-w
$$

where $\frac{1}{2} m v^{2}$ is the kinetic energy of ejection of a $\beta$-particle from an atom within which the potential energy of the particle is $w$ and $h v$ is the quantum of incident energy. The energy $w$ is that which was radiated by the atom during the previous binding of the electron, and equals* $\left(h v_{\mathrm{K}}+h v_{\mathrm{L}}+\right.$ etc. $)$ if the electron occupied a " $\mathrm{K}$ " ring, or $\left(h v_{\mathrm{L}}+\ldots\right)$ if it occupied an "L" in the parent atom. Assuming that the $\mathrm{X}$-rays are absorbed in quanta and that it is not a necessary condition that every atom taking part in the absorption should return at once to the stream the maximum possible quantity of $\mathrm{X}$-radiation, we should obtain groups of electrons of speeds $v_{1}, v_{2}, v_{3}$ etc., emitted from an element $\mathrm{S}$ when X-rays of frequency $v$ fall upon it, given by

$$
\begin{gathered}
\frac{1}{2} m v_{1}^{2}=h v-{ }_{\mathrm{S}}\left(h v_{\mathrm{K}}+h v_{\mathrm{L}}+h v_{\mathrm{M}}+\ldots\right) \\
\frac{1}{2} m v_{2}^{2}=h v-{ }_{\mathrm{S}}\left(h v_{\mathrm{L}}+h v_{\mathrm{M}}+\ldots\right) \\
\frac{1}{2} m v_{3}^{2}=h v-{ }_{\mathrm{S}}\left(h v_{\mathrm{M}}+\ldots\right), \\
\text { etc. }
\end{gathered}
$$

These groups constitute the $\beta$-ray spectrum varying with $v$.

$$
v_{3}>v_{2}>v_{1} \text {. }
$$

* Bohr, Phil. Mag. ser. 6, vol. xxx. p. 412 (1915) gives a discussion of what sbould constitute the quantity in the brackets. Apparently his conclusions lead him to one, viz., the first term in the brackete, but he produces evidence from the separate work of Moseley, Kossel, and Barkla for the inclusion of all the terms as they appear here and in snbsequent expressions. Throughout this paper I have followed the latter method, but at the conclusion it is shown that a better agreement with the theory can be obtained amongst the results if we assume that the energy required to remove a " $K$ " electron to a point of zero potential with no kinetic energy $=h v_{\mathbf{k}}$, the atom readjusting itself subsequent to the removal, (See also O. W. Richardson, 'Electron Theory of Matter,' p. 509 (1916).) 
According to this scheme it must be noted that the so-called " $\mathrm{K}$ " electron is the slowest one, whilst the most rapidly ejected electron is the one that comes from the periphery of the atom, $i$. e. the so-called photo-electron ${ }^{*}$.

In a previous paper $\dagger$ I pointed out that the absorption coefficients of these particles in various gases derived by Beatty and Sadler must be regarded as mean values. If the above scheme is correct, not only has the mean to be taken over the various speeds, but the matter is complicated further by our not knowing the relative numbers possessing the respective speeds. As one might say, we do not know the relative intensities of the respective $\beta$-ray spectral lines, I also produced experimental evidence in support of the above views.

Although it has often been stated that there is a definite " $\mathrm{K}$ " group of electrons associated with " $\mathrm{K}$ " X-radiation, and an "L" group associated with " $L$ " X-radiation, yet I have been unable to find any experimental determination as to which group will have the greater velocity if the parent atoms are emitting simultaneonsly both " $K$ " and " $L$ " X-radiations. The nearest approach to any definite statement was made by Sadler, who pointed out that under certain conditions intense electronic emission from a screen was not necessarily associated with the emission of any (tertiary) X-radiations that could be detected. "For instance, when the secondary exciting beam from silver itself falls upon silver as tertiary radiator, no homogeneons Röntgen radiation is produced, and yet a considerable emission of corpuscular radiation occurs" $\ddagger$.

Finally, some extremely important deductions have been made from the work quoted above, e. g. it is deduced that the maximum velocity of the $\beta$-rays is never greater than that of the parent cathode ray within the discharge-tube.

* It must be pointed out that this statement is not contrary to the experimental results of Barkla and Shearer, who excited first $K$ radiation in a given screen by the incidence of a still harder radiation and then $\mathrm{L}$ radiation in a screen of higher atomic weight, by the same radiation (too soft to produce the $K$ radiation in this latter screen). They then studied the maximum velocity of emergence of the $\beta$-rays from the two screens and found them to be equal. These experiments support this conclusion, but an attempt has been made to push the subject farther. Concomitantly with $\mathbb{K}$ emission, a given screen must be emitting L, $\mathrm{N}$, etc. X-radiations, and what one calls the " $\mathrm{K}$ " electron is probably that emerging from the atom with the smallest velocity of the groups of electrons associated with the emission of the various $\mathrm{X}$-rav spectral lines.

+ Trans. Roy. Soc. S. Africa, vol. viii. pt. 1, p. 82 (1919).

+ Ibid. p. 35ั4. 


\section{Mr. L. Simons on the Beta-Ray Emission from}

In the experiments described below some attempt has been made to find a solution to the following problems :-

1. Is the maximum speed of ejection of an electron from an atom entirely independent of the nature of that atom and dependent only upon the wave-length of the incident radiation?

2. Apart altogether from the question of the diminution in speed of emergence of those $\beta$-rays which have their origin in the deeper layers of the material, what is the precise nature of the distribution of speeds amongst the electrons emitted from the parent atoms when these are exposed to X-rays? How is the distribution affected by $(a)$ the nature of the parent atom, $(b)$ the wave-length of the incident radiation?

3. If the existence of a $\beta$-ray "spectrum" can be proved, what is the interrelation between each $\beta$-ray spectral line and the corresponding $\mathrm{X}$-ray spectral line?

\section{Apparatus.}

The method employed throughout was that due originally to Beatty in his study of the absorption coefficients of the $\beta$-rays. A few modifications were introduced. It was thought that the emission would be simplified by using only very thin films of the various elements. These were As, Se, $\mathrm{Zr}, \mathrm{Ag}, \mathrm{Sn}, \mathrm{Sb}, \mathrm{Ba}, \mathrm{Au}, \mathrm{Pb}$, and $\mathrm{Bi}$. The X-rays which were incident upon these screens in turn were the so-called homogeneous X-radiations, first from silver and secondly from barium *. The primary beam of $\mathrm{X}$-rays was produced by a standard Coolidge tube, and every endeavour was made throughout the whole of the work, a period of about eleven weeks, to keep matters constant. The parallel spark, between point and plate, backed up by the tube measured four inches, and the current in the heating spiral was adjusted so that the point and plate were always just on the point of sparking. This current was four amperes throughout. The barium secondary radiator was a flat cell of $\mathrm{BaO}_{2}$, the front of the cell being tissue-paper, the back card. When this was used an extra aluminium sheet $1 \mathrm{~mm}$. thick was interposed between it and the ionization chamber and other apparatus in order to eliminate the characteristic $\mathrm{L}$ radiation

* The fact that the so-called homogeneous $K$ radiation consists of a series of lines of different wave-lengths, whilst rendering impossible accurate measurements by this method, does not seriously interfere with the main conclusions drawn herein. An attempt is being made to employ really homogeneous radiations and to overcome the necessary mechunical difficulties. 
from $\mathrm{Ba}$. When the silver secondary radiator was used, the front of the ionization chamber, being aluminium $75 \mathrm{~mm}$. in thickness, was sufficient to absorb the $L$ radiation from silver.

The Screens.-These were prepared in the following manner. A brass disk, $12.7 \mathrm{~cm}$. in diameter and $0.17 \mathrm{~cm}$, thick, had a brass rim soldered centrally upon it. The rim was $10.2 \mathrm{~cm}$. in diameter and $0.4 \mathrm{~cm}$. deep. In this manner a flat cell was produced $10.2 \mathrm{~cm}$. in diameter and $0.4 \mathrm{~cm}$. deel. Eleven such cells were prepared. These cells were filled with paraffin-wax, the surtace being scraped down flat and level with the upper edge of the rim and polished with natural graphite. To obtain films of Au, Sn, and Ag electrodeposition from the double cyanide was employed. A brass cylinder, open at both ends, about $10 \mathrm{~cm}$. in diameter and about $7 \mathrm{~cm}$. high, was stood upon the graphited wax plate $u$ (fig. 1). The inside of this cylinder was raxed so as to

Fig. J.

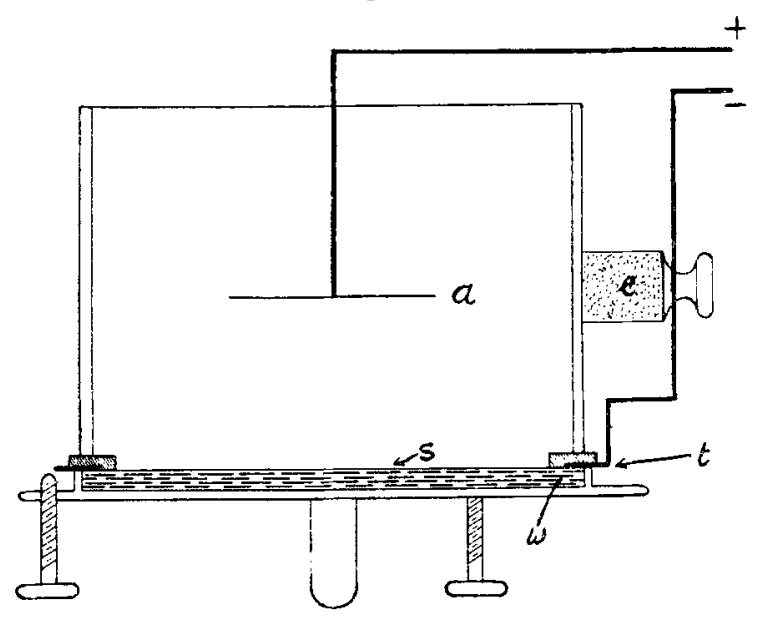

prevent contamination, $e$ is an ebonite block. By an arrangement of an indiarubber ring sealed round the edge of the cylinder, and an annular tinfoil electrode $t$ stuck on the indiarubber ring, good electric contact could be made with the graphite surface. The electroplating solution was then poured into the cell, a suitable ancde $a$ dipped in, and deposition started on $\mathrm{S}$ and judged by the eye. In the case of these three substances, the films were uniform and so 
thin that the graphite backing could easily be seen through them.

Films of the other substances were obtained in the following manner. It was necessary to obtain an adberent conducting surface in each case. The surface had to be conducting in order that the electrostatic capacity of the ionization chamber, of which the surface really formed the back, shouid remain unaltered when the various screens were substituted for one another. This conducting surface had also to be made of some material of low atomic weight from which there is no electronic emission. To obtain a degree of uniformity, the graphited wax surface was placed horizontally, face uppermost, and an inverted electric hotplate was brought down for a few moments to within a distance of about $0.5 \mathrm{~cm}$. from the surface. The graphite surface cracks and the paraffin-wax comes up through the fissures of retreat. If the process is watched carefully and is stopped at the right moment, the whole surface is conducting, as tested by an electroscope, and it will take a powder in a way that polished graphite cannot. It also remains quite plane. Pure $\mathrm{As}$, Se, $\mathrm{Zr}, \mathrm{Bi}$, and $\mathrm{Sb}$ were very finely powdered in a mortar and lightly dusted over the prepared plates, the larger grains being wiped off and the plates being vigorously tapped in order to get rid of any particles not properly adhering to the wax. Microscopic examination showed that each plate was covered with a uniform layer of minute grains. No estimate of the size of the grains was made. Each plate was tested for electrical conductivity. Barium peroxide was similarly dusted on a plate for the $\mathrm{Ba}$ screen and red-lead for the $\mathrm{Pb}$ screen. $\mathrm{An}$ eleventh screen was made contuining a flat sheet of carbon (cut from a dynamo brush) instead of the usual paraffin-wax. Finally, each disk was provided with three screw-legs round the edge outside the rim, and all the parts except the prepared screen and the back of the disk were coated with a thin layer of wax and rubbed with graphite.

A small brass conical gange-piece was made $1.45 \mathrm{~cm}$. high, which was placed on a sheet of glass and the screen placed over it. The screw-legs were now adjusted until each part of the surface of the screen just touched the apex of the gauge-piece. The screens were then ready to be placed in the ionization chamber, but before doing so each was placed for a short while under the receiver of an air-pump in which the pressure was maintained at about $2 \mathrm{~mm}$. 
The ionization chamber is shown in fig. 2. To the bottom of the brass cylindrical case a sheet of aluminium $(a) \cdot 75 \mathrm{~mm}$. thick was sealed on with Chatterton compound and fixed with a screwed-on brass ring. The heavy top was ground

Fig. 2.
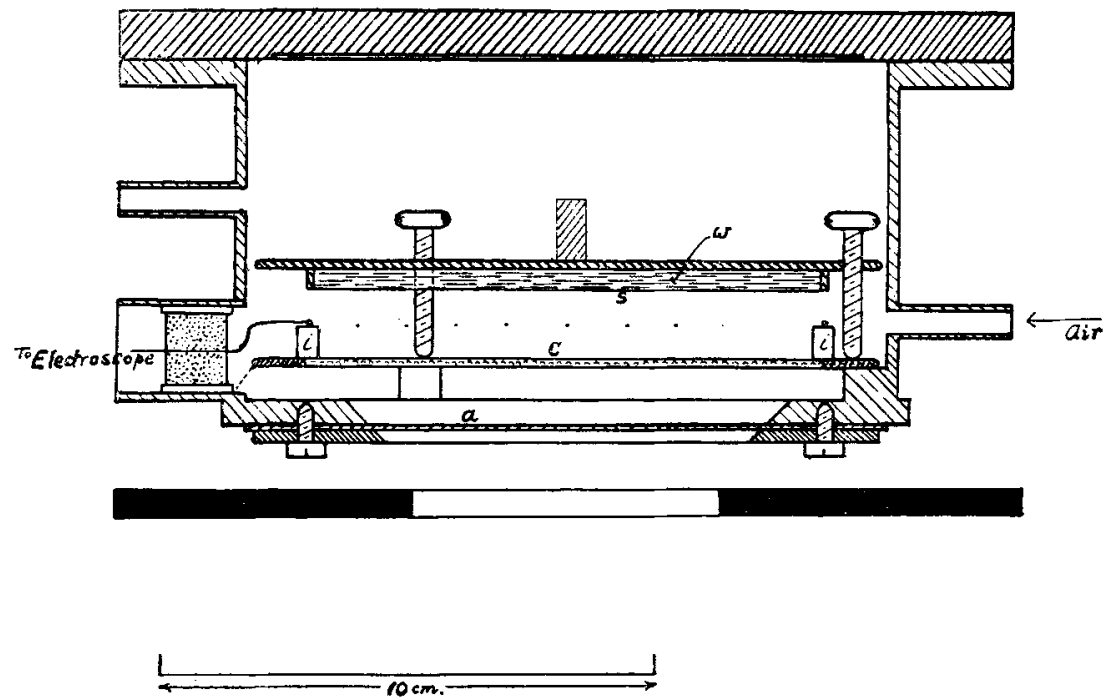

flat for easy removal, the sealing material in this case being a soft mixture of bees'-wax and vaseline. A pure carbon plate (c), about $11 \mathrm{~cm}$. in diameter and $1.5 \mathrm{~mm}$. thick, was mounted flush within a flat brass ring; this ring with its plate rested on three small chairs round the bottom of the case, and when a screen was put in, its legs rested on the brass ring. On the ring there were three small sulphur beads (i), which supported an electrode connected to a Wilson electroscope, the electrode being made of radial carbon filaments. Finally, all the brass parts within the case were painted with a mixture of sugar-water and artificial graphite. Lead diaphragms were arranged so as to keep the $\mathrm{X}$-radiation from falling anywhere but within the prepared surface of the screen.

The only gas used throughout the experiments was air, and the pressure within the chamber could be varied from a fow millimetres up to atmospheric pressure. Before passing into the chamber the air was roughly dried by bubbling it 
through sulphuric acid. A fresh supply of air constantly passed through the chamber during the experiments.

Throughout the first set of experiments the silver plate was used as the secondary radiator. First the carbon screen was placed in position, the pressure within the ionization chamber adjusted, and the mean ratio obtained of the ionization in it to that in a standardizing electroseope 12 to 14 points on the curves being obtained within the range from zero up to atmospheric pressure. Another screen was substituted and the process repeated. The screens were not used in any definite order. The barium secondary radiator (with its accessory aluminium plate for cutting out the $\mathrm{L}$ radiation) was now substituted for the silver one, and the whole process repeated, again using the eleven screens in no definite order.

\section{Experimental results.}

Fig. 3 (Pl. III.) gives the points obtained in using the eleven screens successively with silver as radiator, and fig. 4 with barium as radiator. No corrections whatever have been made in putting down the points, the air effect and the normal leak of the instruments being so small that they could be neglected.

The ordinates of the carbon curve were subtracted from those of the other curves. Each resulting curve would represent the ionization produced in air at various pressures by the $\beta$-particles emerging from the respective screens. There is a critical pressure at which the range of the $\beta$-particle is just equal to the thickness of the ionization chamber: viz., $1.45 \mathrm{~cm}$. Above this pressure the curves become horizontal straight lines, for the $\beta$-particles are now completely absorbed in the air. Below this pressure some of the energy of the particles will be lost by their being absorbed in the carbon front of the chamber.

The resulting ten curves, say with silver as secondary radiator, differ widely from one another in their maximum ordinate. In other words, the total ionization by the $\beta$-particles in these experiments shows a considerable variation over the range of substances used. It must be remarked at once that this variation here has but little meaning. It is known that the intensity of the $\beta$-ray emission increases with increasing atomic weight of the screen, but apart from this, as the films of substances radiating were so exceedingly thin to a certain extent of variable thickness, but by no means thick enough to absorb to any extent the $\beta$-particles produced from the side of the 
material in contact with the graphite surface, no importance can therefore be atrached here to the fact that the total ionization observed difiers widely for the various screens.

Figrs. 5 and 6 (Pl III.).-For the purpose of comparing the curves along their non-linear portions, each was scaled up to the same misimum ordiuate*. The result is shown in fig. 5 (Pl. III.), which might be called the cathode ionization curves from the ten sereens, silver as radiator, and in fig. 6 (Pl. III.), harium as radiator.

In the paper previously referred to, the writer has shown Eully how the first derivatives of the curves shown in figs. 5 and $\dot{6}$ (Pl. III.) give the density of the ionization in a chamber containing air at $0^{\circ} \mathrm{C}$ and $76 \mathrm{~cm}$. pressure at a distance $\frac{p}{76} \times \frac{27 \ddot{b}}{27 \dot{3}+\theta} \times 1.45 \mathrm{~cm}$. from the screen, where $p$ is the pressnre at which an ordinate such as $A B$ is drawn, $1.45 \mathrm{~cm}$. the thickness of the ionization chamber uset, and $\theta$ the mean temperature of the experiment, about $24^{\circ} \mathrm{C}$. in this case. This expression has been used in order to convert values of $p$ into corresponding values of the distance from the screen as measurer in air at $6^{\circ} \mathrm{C}$. and $76 \mathrm{~cm}$. pressure. The ordinate $\mathrm{AB}\left(=\mathrm{N}_{x}\right)$ measures the total ionization by $\beta$-rays in air (at $0^{\circ} \mathrm{C}$. and $76 \mathrm{~cm}$. pressure) in the region from the screen up to an imaginary layer $0.1 \mathrm{~cm}$. from the screen.

Fig. 7 (Pl. III.).--When the curves of figs. 5 and 6 (PI. III.) were first drawn, there seemed to be little order about their sequence, except that in fig. 5 (PI. III) the curve for the silver screen was lowermost and in fig. 6 (Pl. III.) the barium curve lowermost. In order to slow up any sequence, fig. 7 (Pl. IIL.) was drawn. This figure has for abscissæ the atomic numbers of the elements of the screens, whilst the ordinates are taken directly from figs. 5 and 6 (Pl. III.) as follows. The length (;B (fig. 5) represents the total ionization by $\beta$-rays in air (at $0^{\circ}$ C. and $76 \mathrm{~cm}$. pressure) included within the region from an imaginary plane $0.1 \mathrm{~cm}$. from the screen up to the front face of the chamber; it is therefore a measure of the $\beta$-ray energy crossing this plane, and equals $\left(\mathrm{N}_{0}-\mathrm{N}_{x}\right)$. The line $\mathrm{CB}$, at the $0 \cdot 1 \mathrm{~cm}$. mark, is drawn right across the 10 curves, and its various lengths raised above the respective elements

* The simplest physical interpretation of such an adjustment is to imagine the number of atoms at the surface of each screon so packed that the $\beta$-ray emission from e:tch screen gives rise to equal total ionization in the air of the chamber for complete absorption of the particles.

Phil. Mag. S. 6. Vo1. 41. No. 241. Jan. $1921 . \quad$ K 
placed in order of atomic number along the horizontal axis of fig. 7 (Pl. 1II.). This process is repeated for other distances from the screens. Thus, since the curves figs. 5 and 6 (Pl. ILI.) refer to equal total ionizations, a high ordinate on fig. 7 (Pl. III.) at any point indicates a larger proportion of higher velocity electrons passing that plane, and rice versâ.

The question arises that the marked variations in the shape's of the curves of figs. 5 and 6 (Pl. III.) might be due entirely to the ionization in the chamber by the variable tertiary $\mathrm{X}$-radiation from the successive screens, superposed on the ionization by the $\beta$-radiations which has a uniform function for each of the screens. Some of the reasons for this riew being untenable are set down below. Though this tertiary $\mathrm{X}$-radiation must he present, the ionization produced by it, in comparison with that produced by the $\beta$-radiations from the screens, must be negligibly small: Barkla and Shearer neglested this effect in their work already cited.

(1) The total ionization in the air in the chamber with earbon ends produced by the incident beam of $\mathrm{X}$-rays is quite small, even at atmospheric pressure, in comparison with that produced by the $\beta$-radiations from the screens, and it is presumed that the effect of the tertiary X-radiation from the screen would only be a fraction of that due to the secondary X-radiation.

(2) The linear portions of the curves in fig. 3 (Pl. IJI.) could not be parallel to each other if the effect of tertiary radiation were appreciable. The greater the effect of tertiary radiation, the more sloping wonld these lines become.

(3) For a given substance, the thinner the radiating film, the smaller will be the ratio of ionization by tertiary $\mathrm{X}$-rays to that by $\beta$-rays in a comparatively thin layer of air. The absorption coefficient of the $\beta$-rays in the radiating film itself is extremely great, whilst that of the tertiary $\mathrm{X}$-rays is comparatively small. If a film were prepared of such a thickness as just to absorb the $\beta$-rays generated at its face in contact with the graphite, increasing the thickness would not increase the tertiary $\mathrm{X}$-ray emission.

(4) The apparent independence of the shape of the curves in fig. 7 (Pl. III.) on the relative dimensions of the curves in figs. 3 and 4 . If the ionization by the tertiary X-rays from the screens were finite, it would, of course, be included in the dimensions of the curves figs. 3 and 4 (Pl. III.). 
(5) Sadler's remark that the emission of corpuscular raliation is not necessarily associated with the emission of tertiary $\mathrm{X}$-radiation. This statement will be examined in more detail later.

There are many points of interest in fig. 7 (Pl. III.). First, that ordered curves are obtained for the screens used. Again, if the degree of scattering is the same for all screens, and the phenomenon does not depend apon the actual number of $\beta$-particles involved, then, of the screens used, the silver atom emits the greatest proportion of high-speed electrons when excited by silver X-radiation, and similarly for the barium atom when excited by barium X-radiation.

Consider for the moment the effect of silver X-rays on the screens successively. There are two important effects that have to be distinguished. The first is that the $\mathrm{K}, \mathrm{I}$, $M$, etc. radiations are excited in those elements below, and only L, M, etc. radiations are excited in those elements abore the atomic weight of silver. The second effect is much more obscure. We do not know the relative numbers of atoms radiating each of the spectral lines. With regard to the latter effect, it appears in photographic images of the $\mathrm{X}$-ray spectra and in ionization work generally that the lines of longer wave-length are the more intense. This can be understood, for the waves of shorter wave-length would soon pass over the atom, and, reacting on an outer ring, be transformed partly into longer waves, and part of the energy would go into the new corpuscles produced. 'The complete interpretation of the curves in fig. 7 (Pl. III.) would necessitate a knowledge of the relative intensity of the various $X$-ray spectral lines from a thin film of the element.

There is still another point of very great interest in fig. 7 . In 1912, J. C. Chapman, working on homogeneous X-rays, arrived at the formula*

$$
W_{\mathrm{K}}=\frac{\mathrm{l}}{2}\left(\mathrm{~W}_{\mathrm{L}}-48\right),
$$

where $W_{\mathbf{L}}$ is the atomic weight of an element emitting $\mathrm{L}$ radiation, $W_{K}$ that of an element emitting $K$ radiation of the same absorbability in aluminium.

This formula yields the result that the $K$ frequency from ar senic equals the $\mathrm{L}$ frequency from gold. Moseley expressed practically the same result in a different form $\dagger$. He gare

* Proc. Roy. Soc. A. vol. Ixxxvi. p. 447 (1912).

t Phil. Mag. ser. 6, vol. xxvii. p. 712 (1914).

K 2 
the $\mathrm{K}_{a}$ frequency of the elements as

and also

$$
v_{\mathrm{K}_{\alpha}}=\left(\frac{1}{1^{2}}-\frac{1}{2^{2}}\right)(\mathrm{N}-1)^{2} n_{0}
$$

$$
v_{L_{\alpha}}=\left(\frac{1}{2^{2}}-\frac{1}{3^{2}}\right)(\mathrm{N}-7 \cdot 4)^{2} n_{0}
$$

where $\mathrm{N}$ is the atomic number of the element and ${ }_{0}$ the fundamental frequency of line spectra $(=109720 \times$ velocity of light). These formula give the $K_{a}$ frequency of :rsenic equals the $L_{a}$ frequency of lead. The result is apiroximate ly the same as Chapman's.

Reference to the curves in fig. 7 (Pl. III.) will show that this result is applicable not only to $X$-ray emission lut analogously to $\beta$-ray emission. This is clearer in the dotted curves, the distribution in speeds of the electrons about an arsenic screen being similar to that about a lead scren.

There are appearances, too, that the effect is carried on through the range of the elements.

An attempt to detect groups of $\beta$-particles possessing subspeeds and to determine the numerical relations between them. (Figs. 8 and 9, Pl. III.)

The range of the $\beta$-particles and the law of absorption: that they follow are matters of some obscurity. Whiddington set himself to determine whether the range was proportional to $\mathrm{E}$ or $\mathrm{E}^{2}$, where $\mathrm{E}$ is the energy of the particle. IV. Wilson's * results give $\mathrm{E}^{32}$ for the rays from radioactive substances. J. J. Thomson † and Bohr $\ddagger$ have both deduced complex formulæ involving $\mathbf{E}^{2}$ as one of their terms. The diffeulty arises from the impossibility of determining the diminution in energy along the complex path of the $\beta$-ray. Wilson showerl that only a complex distribution of velocities amongst the $\beta$-rays from radioactive substances would give rise to an exponential law of absorption, whilst Sadler stated that his slow-moving homogeneous $\beta$-rays were absorbed according to an exponential law.

In a previous paper $\$ I$ deduced tentatively a result based upon an exponential law of absorption. The major speed $v_{t}$

* Proc. Roy. Soc. A. 1xxxiv. p. 141 (1910).

+ 'Conduction of Electricity thro'gh Gases,' p. 381 (1906).

$\ddagger$ Phil. Mag. ser. 6, vol, xxv. p. 28 (1913).

$\S L$ Lic, cit. 
of the $\beta$-rays from gold (produced by the incidence of silver $\mathrm{X}$-rays) was calculated from the expression

and the minimum speed $v_{2}$ from

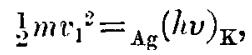

$$
{ }_{2}^{1} m r_{2}^{2}={ }_{A g}(h i)_{\mathrm{K}}-{ }_{A u}\left(h v_{\mathrm{L}}+h v_{\mathrm{M}}+\ldots\right) \text {. }
$$

The ratio of $v_{1}$ to $v_{2}$ agreed weil with the experimental result obtained from the logarithmic absorption coefficients of the two sets of rays and by assuming Whiddington's fourth-power law $\lambda v^{+}=$constant, where $\lambda$ is the $\log$ arithmic absorption coefficient.

I do not think it safe to assume an exponential or any theoretically derived law * in connexion with these experiments. The problem of the range of the sub-groups has therefore been attacked in a totally different manner. Unfortunately, it has to presume the existence of the subgroup, but the result obtained points strongly to the accuracy of this assumption and also to the general agreenent with the photo-electric hypotbesis of the sub-groups.

Figs. 8 and 9 (Pl. III.).-A close examination of figs. 5 and 6 (Pl. III.) shows that the curves cannot be members of the same family, but that the irregularities might be due to the superposition on curves belonging to the same family of other curves varying among themselves. Figs. 8 and 9 represent the results of an attempt to analyse geometrically the curves of figs. 5 and 6 (Pl. III.).

Suppose these curves, figs. 5 and 6 (Pl. III.), to be represented by $\mathrm{N}_{x}=\mathrm{N}_{0} f(x)$, where $\mathrm{N}_{0}$ is tne ionization due to the total absorption of the $\beta$-ray energy in the air of the chamber, $\mathrm{N}_{x}$ the total ionization in air at $0^{\circ} \mathrm{C}$. and $76 \mathrm{~cm}$. pressure between the illuminated screen and the imaginary plane $x \mathrm{~cm}$. from the screen. The variation of the density of ionization with distance from the screen is given by $\mathrm{N}_{0} f^{\prime}(x)$, and the variation of a logarithmic absorption coefficient of the $\beta$-particles with the distance from the screen by $\frac{d}{d x} \log _{e} \mathrm{~N}_{0} f^{\prime}\left(x^{\prime}\right)$.

If the curves of figs. 5 and 6 (Pl. III.) could be represented by $\mathrm{N}_{x}=\mathrm{N}_{0}\left(1-e^{-\lambda x}\right)$, this operation would yield $-\lambda$ constant. The value of $\lambda$ so obtained gives a measure

* The theoretically derived laws deal only with radiators without a boundary; in practice a boundary is necessary. The condition of absorption in the gas near the boundary of the screen will be different from that obtrining in the central region. Unless a guard-ring method were employed, an empirical formula would be required for each chamber of different dimensions. 


\section{Mr. L. Simons on the Beta-Ray Emission from}

of the speed of the particles from Whiddington's law, $\lambda v^{4}=$ constant ${ }^{*}$.

But the operation

$$
\frac{d}{d x} \log _{e} \mathrm{~N}_{0}\left(1-f^{\prime}\left(v^{i}\right)\right)
$$

performed on the exponential curves would also yield $-\lambda$, meaning that only if the original curves were exponential, plotting the slope of the logarithms of residues such as $\mathrm{BC}$, fig. 5 (Pl. III.), would result in the same constant, represented in figs. 8 and 9 (Pl. III.) by a horizontal straight line.

In this work involving unknown functions, in which the operations have to be performed geometrically, the latter process involving one differentiation is possible, although the physical interpretation of the resulting curves is not so clear as if the former process had been adopted. Figs. 8 and 9 (RI. III.) show the results of operating by the latter method on the curves of figs. 5 and 6 (Pl. III.). As these curves are ronghly logarithmic, it was thought that this shorter method would show up just as accurately as the method involving two differentiations where the function represented by the one part of the curve changed, if at all, into that represented by the remainder of the same curve. Eigs. 8 and 9 show, of course, that none of the curves of figs. 5 and 6 are exponential. Portions of the curves seem to be represented by the same function, definite changes taking place at the points marked.

It is not claimed that the resulting lines are true in their smaller detail. A large portion of the end has been omitted in consequence of the impossibility of performing the graphical operation, whilst there can be little accuracy at the beginning becatuse of the difficulty of measuring the small ionization currents. It is claimed that the largest features of the curves are fairly correct. It is presumed that the positions of the minima on these curves give the range of the sub-group of electrons $t$.

* Proc. Roy. Soc. A. vol. lxxxvi. p. 375 (1912).

† A little consideration will show that if there were two homogeneous groups of electrons emitted from a given. screen and superposed, each following an exponential law of absorption, the eurve in this case, drawn in the manner of figs. 8 and 9 (Pl. III.), would fall gradually to a minimum, marking the range of the slower group, after which it would run on horizontally. If, on the other land, the logarithmic absorption coefficient, as it appears in these experiments, increases with distance from the screen, the resulting curve, drawn in the same manner, would still show a minin um or a decided change in direction approximately at the range of the slower group. 
Thin Films of Flements exposed to Röntgen Rays. 135

We can employ the expressions for the photo-electric equation given in the introduction in order to calculate what shonld be the theoretical value of the energies of the electrons of the K, L, or M type sent out from the various screens when each is subjected, first to silver and second to barium $\mathrm{X}$-rays. In the absence of any definite knowledge of the relative intensities of the $\alpha, \beta, \gamma$, etc. lines of the $\mathrm{K}, \mathrm{L}, \mathrm{M} \mathrm{X}$-rays we must confine ourselves throughout to the $\alpha$ lines.

TABLe I.

\begin{tabular}{|c|c|c|c|c|c|c|c|c|c|c|}
\hline \multirow[b]{2}{*}{$\begin{array}{l}\text { Element } \\
(\mathbf{S}) \text {. }\end{array}$} & \multirow[b]{2}{*}{$\begin{array}{l}\text { At. } \\
\text { No. }\end{array}$} & \multicolumn{3}{|c|}{$\begin{array}{l}\text { Values of } \\
v / n_{0^{*}}\end{array}$} & \multicolumn{3}{|c|}{$\begin{array}{l}\text { Incidence of Silver } \\
\text { (K) X-rays. }\end{array}$} & \multicolumn{3}{|c|}{$\begin{array}{l}\text { Incidence of Barium } \\
\text { (K) X-rays. }\end{array}$} \\
\hline & & $\mathbf{K}_{a}$ & $\mathbf{L}_{a}$ & $\mathrm{M}_{a}$ & (a). & $(b)$ & (c). & $(d)$ & $(e)$. & $(f)$. \\
\hline & 33 & 783 & 94 & 15 & $\gamma_{41}$ & 1524 & 1618 & 1491 & 2274 & 2368 \\
\hline $\mathrm{Se}$ & 34 & 835 & 101 & 16 & 681 & 15 & 16 & 14. & 22 & 2367 \\
\hline & 40 & 1156 & 150 & 23 & 304 & $14+30$ & 161 & 1054 & 221 & 2360 \\
\hline $\mathrm{Ag}$. & 47 & 1633 & 220 & $36^{\circ}$ & $\ldots$ & 1377 & 159 & 494 & 2127 & 2347 \\
\hline Sn. & 50 & 1871 & 254 & 43 & $\ldots$ & & & 215 & & 2340 \\
\hline $\mathrm{Sb}$ & 51 & 1950 & 265 & 46 & . & 1322 & 158 & $12 Z$ & 2072 & 2337 \\
\hline $\mathrm{Ba}$. & 56 & 2383 & 328 & 60 & $\ldots$ & 1245 & 157 & $\ldots$ & & 2323 \\
\hline$A_{1}$ & 79 & $\ldots$ & 717 & 156 & $\ldots$ & 760 & 1477 & $\ldots$ & 1510 & 2227 \\
\hline $\mathrm{Pb}$. & 82 & $\ldots$ & 777 & 173 & $\ldots$ & 683 & 14 & $\ldots$ & 1483 & 2210 \\
\hline Bi $\ldots$ & 83 & $\ldots$ & 797 & 180 & $\ldots$ & 656 & 1453 & $\ldots$ & 1406 & 2203 \\
\hline
\end{tabular}

TABLE I.-Columns 3 and 4 give the values of $v / n_{0}$ for the $\mathrm{K}_{\alpha}$ and $\mathrm{L}_{\alpha} \mathrm{X}$-ray spectral lines from the various elements S. These values have been obtained by interpolation from the observed values quoted by Vegard *; the values for the $M_{a}$ line are interpolated from the formula $\dagger$

$$
v_{\mathrm{M}_{\alpha}} / n_{0}=\frac{7}{144} \mathrm{~N}^{2}-2 \cdot 37 \mathrm{~N}+40 \text {. }
$$

Column $(a)$ is obtained from the expression

$$
{ }_{\mathrm{Ag}}\left(v / n_{0}\right)_{\mathrm{K}_{\alpha}}-{ }_{\mathrm{S}}\left[\left(v / n_{0}\right)_{\mathrm{K}_{a}}+\left(v / n_{0}\right)_{\mathrm{L}_{\alpha}}+\left(v / n_{0}\right)_{\mathrm{N}_{a}}+\ldots\right],
$$

column $(b)$ by omitting the first of the terms within the square brackets, and column (c) the first and second terms from the square brackets. Columns $(d),(e)$, and $(f)$ in a similar manner when ${ }_{\mathrm{Ba}}\left(v / n_{0}\right)_{\mathrm{K}_{\alpha}}$ is substituted for ${ }_{\mathrm{Ag}}\left(v / n_{0}\right)_{\mathrm{K}_{\alpha}}$ in the first part of the expression.

* I. Vegard, Phil. Mag. ser. 6, vol, xxxv. pp. 293, 301, 316 (1918).

+ Loc. cit. 
According to the theory outlined in the introduction, the numbers in these six columns, if multiplied by the constant $n_{0} h$, gire respectively the energies of the $\bar{K}, L$, and $M$ electrons omitted by the various sereens when they are subjected first to $\mathrm{Ag} \mathrm{X}$-rays and then to $\mathrm{Ba} \mathrm{X}$-rays, the $\mathrm{K}$ electrons being the least rapid and the $\mathrm{M}$ electrons the most rapid ones.

This close study by Beatty's "pressure variation" method has led me to the conclusion that it is extremely difficult to distinguish any variation in the maximum range in the $\beta$-rays emitled by the rarious screens all exposed to rays of one type ; the practical reason is that the be:m of the $\beta$-rays is so attenuated, both by the transformation of its energy into ions and by diffusion near is extreme range, and theoretically from the fact that the numbers in column (c) or in column $\left(f^{\prime}\right)$, Tạble I., are so close together, that the electrons, whose rauge according to Whiddington's fourthpower law should be proportional to the squares of these numbers, are almost indistinguishable. Or better, the electrons of maximum energy are the peripheral electrons whose potential energy within the parent aton is negligibly small, whatever the atom may be, in comparison with the incident quantum. They emerge $"$ ith practically the whole of the energy of the incident quantum, and their range will be almost independent of the nature of the parent atom, as Barkia and Shearer have already shown. Those numbers referring to the ranges which these experiments might be able possibly to distinguish from each other or from the mean maximum range are italicised in Table $I$. These are taken out in Table II. One further point wortb mention is that when Silver $X$-rays $(K)$ type are incident on silver or on elements just above silver in atomic weight, there is no $\mathrm{K}$ emission of X-rays, but groups of electrons possessing a large amount of energy. A similar statement is true for Barium (K) X-rays on barium. This accounts for Sadler's observation.

The distances in the two columns marked "range" are obtained from the positions of the minima of the curves in figs 8 and 9 (Pl. III.) respectively. According to this work, these are approximately the distances traversed in air at $0^{\circ} \mathrm{C}$. and $76 \mathrm{~cm}$. pressure by the groups of electrons having ranges which could be distinguished by this method from those of the fastest groups. From Whiddington's fourth-power law, which must he regarded as approximate, it follows that $\mathrm{E} / d^{\frac{1}{2}}$ should be constant, where $\mathrm{E}$ is the kinetic energy of the electrons of range $d$ in air. Apart from the 
three results, which are obviously in error, it will be seen that there is a rough agreement with this law for the minor groups.

TABLE II.

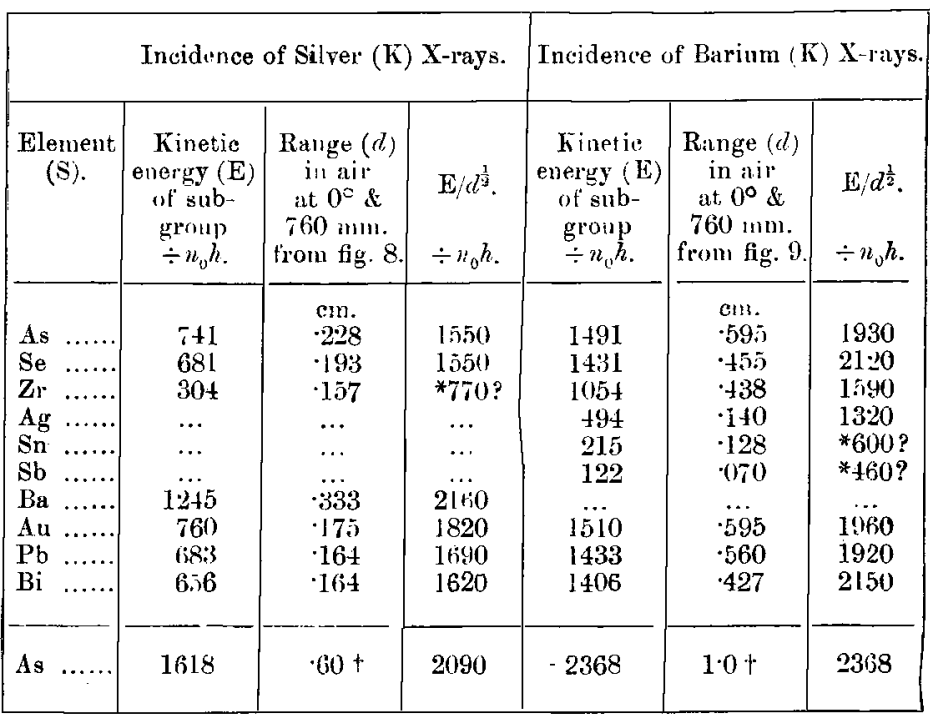

* These numbers are got from the small ranges where the error must be considerable.

+ Obtained from figs. 5 and 6 (Pl. III.). These are the maximum ranges for the incidence of $\mathrm{Ag}$ and Ba $\mathrm{X}$-rays respectively.

\section{Some further comsiderations on the potential energy of the electrons.}

There seem to be two distinct points of view : (1) If an electron be removed from a " $K$ " ring an " $L$ " electron falls into its place, an " $M$ " electron into the place of the " $L$ " electron, and so forth. During this process the one atom would yield a series of line spectra. This is the view adopted up to the present, and also that all the atoms of a given substance exposed to $X$-rays of a given type are not necessarily depleted originally of $K$ electrons-a neighbouring atom may be depleted of an $L$ electron or an $M$ electron. (2) If an electron be removed from a $\mathrm{K}$ ring, this ring readjusts itself from one stable state to the next, during which there is an emission of $\mathrm{K}$ radiation. It seems to me that according to (1) the potential energy of the $K$ electron should be $\left(h v_{\mathrm{K}}+h v_{\mathrm{L}}+\right.$ etc. $)$, and according to $(2)$, only $\left(h v_{\mathrm{K}}\right)$. 
Table III. has been prepared according to this latter scheme, and the results show a very much better agreoment. than is shown by Table II. prepared from the former scheme.

TABLE III.

\begin{tabular}{|c|c|c|c|c|c|c|c|c|}
\hline \multirow{3}{*}{$\begin{array}{l}\text { Sereen } \\
(8) .\end{array}$} & \multirow{2}{*}{\multicolumn{2}{|c|}{$\begin{array}{l}\text { Values of } \\
v / n_{6}\end{array}$}} & \multicolumn{3}{|c|}{$\begin{array}{c}\text { Incidence of Silver }(\mathbf{K}) \\
\text { X-rays. }\end{array}$} & \multicolumn{3}{|c|}{$\begin{array}{c}\text { Incidence of Barium }(\mathbf{K}) \\
\text { X-rays. }\end{array}$} \\
\hline & & & \multirow{2}{*}{$\begin{array}{l}\text { Kinetic } \\
\text { energy } \\
\text { (E) of } \\
\text { sub- } \\
\text { group } \\
\stackrel{-}{-} n_{0} h \text {. }\end{array}$} & \multirow{2}{*}{$\begin{array}{l}\text { Range } \\
(1) \text {. } \\
\text { onl. }\end{array}$} & \multirow{2}{*}{$\begin{array}{l}\mathrm{E} / d^{\frac{1}{2}} . \\
\div n_{0} h .\end{array}$} & \multirow{2}{*}{$\begin{array}{l}\text { Kinetic } \\
\text { energy } \\
\text { (E) of } \\
\text { sub- } \\
\text { group } \\
\div n_{0} h . \\
\end{array}$} & \multirow{2}{*}{$\begin{array}{l}\text { Range } \\
(d) . \\
\text { cm. }\end{array}$} & \multirow{2}{*}{$\begin{array}{l}\mathbf{E} / d^{\frac{1}{2}} \\
\div n_{0} h\end{array}$} \\
\hline & $\mathrm{K}_{a}$. & $\mathrm{L}_{a^{\prime}}$ & & & & & & \\
\hline As . & 783 & $\ldots$ & 850 & 0.228 & 1780 & 1600 & 0.595 & 2070 \\
\hline Se.. & 835 & $\ldots$ & 798 & 0.193 & 1820 & 1548 & 0.455 & 2300 \\
\hline $\mathrm{Zl} \cdot \ldots$ & 1156 & $\ldots$ & 477 & 0.157 & $1200 ?$ & 1227 & 0.438 & 1860 \\
\hline $\mathrm{Ag} \ldots$ & 1633 & & & & & 750 & $0 \cdot 140$ & 2010 \\
\hline $\sin \ldots$ & 1871 & 254 & 1379 & $\ldots$ & $\ldots$ & 512 & $0 \cdot 128$ & 1430 \\
\hline $\mathrm{Sb} \ldots$ & 1950 & 265 & 1368 & & & 433 & 0.070 & 1640 \\
\hline $\mathrm{Ba} \ldots$ & 2383 & 328 & 1305 & 0.333 & 2200 & & & \\
\hline Au ... & $\ldots$ & 717 & 916 & 0.175 & 2190 & 1666 & 0.595 & 2160 \\
\hline $\mathrm{Pb} \ldots$ & $\ldots$ & 777 & 856 & $0 \cdot 164$ & 2110 & 1606 & 0.560 & 2150 \\
\hline $\mathrm{Bi} \ldots$ & $\ldots$ & 797 & 836 & 0.164 & 2070 & 1586 & 0.427 & 2430 \\
\hline As $\ldots$ & $\ldots$ & $\ldots$ & 1618 & 0.60 & 2090 & 2368 & $1 \cdot 0$ & 2370 \\
\hline
\end{tabular}

Mean of all the ralues of $\mathrm{E} / d^{\frac{1}{2}} \div n_{0} h=2 \mathrm{co0}$.

TABLE IIT.-Columns 2 and 3 are taken from Table I. Column 4 is obtained from the expression

$$
{ }_{A \mathrm{~g}}\left(v / n_{0}\right)_{\mathbf{K}_{\alpha}}-{ }_{\mathbf{g}}\left(v / n_{0}\right)_{\mathbf{K}_{\alpha} \text { or }} \mathbf{L}_{a},
$$

the value for $K_{a}$ being employed in the latter term for those screens of atomic number lower than that of Silver. Similarly, column 7 is obtained by substituting ${ }_{\mathrm{Ba}}\left(v / n_{0}\right)_{\mathrm{K}_{\alpha}}$ for the former term, and employing the values for $K_{a}$ in the latter term for those screens below the atomic number of Barium, and $\mathrm{L}_{a}$ for those above that of Barium. The values. of As at the end are taken from Table I.

It will be seen that the values for the constant agree very much better : mong themselves than is shown in Table II.

Taking $m=8.8 \times 10^{-28} \mathrm{gm} ., a=2.1 \times 10^{40}$ in air at $0^{\circ} \mathrm{C}$. and $76 \mathrm{~cm}$. pressure (within an accuracy of 15 per cent. according to Whiddington), $n_{0}=3.3 \times 10^{15}$ sec. $^{-1}$ (Rydberg's constant), $h=6.6 \times 10^{-27}$ erg. sec. (Planck's constant), we 
obtain for the constant* observed in Tables II. and III. for $\mathrm{E} / n_{0} h a^{\frac{1}{2}}$ the value 2930. Bohr + , however; calculates from theoretical considerations that Whiddington's " $a$ " should have the value $1 . \mathrm{I} \times 10^{40}$ for air at a pressure of $76 \mathrm{~cm}$. and at $15^{\circ} \mathrm{C}$. for slowly moving electrons. Using Bohr's value corrected to $0^{\circ} \mathrm{C}$., we obtain the result $210^{\circ} 0$ for the theoretical value of the constant tabulated in Tables II. and III.

It will be seen that the values for the constant in Table III. show better agreement amongst themselves and with the theoretical value than is shown in Table II. The mean value in Table III. is 2000 , whilst the separate values in Table II. differ so widely that it does not appear legitimate to take a mean value at all. The direct conclusion is that each atom is associated with the emission of one quantum only, and that entirely diflerent atoms of a homogeneous substance emitting various spectral lines concomitantly are associated with the $\mathrm{K}, \mathrm{L}$, or $\mathrm{M}$ radiations; but further experiment must decide this important conclusion.

Finally, it must be clearly stated that the method by which these curves have had to be analysed precludes all possibility of an accurate determination of the rances of the sub-groups as it turns on the discrimination of those points in the curves of fiys. 5 and 6 (Pl. III.), where the function represented by the one portion of each curve changes into that represented by the proximate position.

To me, the surest evilence for the existence of the subgroups rests in figs. 8 and 9 (Pl. III.), roughly conforming. as they do to the requirements of the photo-electric equation. 'The ten curves of fig. 8 (PI. III.) divide themselves into two distinct sections: those of the one section being below, and those of the other section above the silver curve, the positions of the minima, representing the range of the subgroup, approaching nearer and nearer to the screen as we pass up from As to $\mathrm{Se}$ to $\mathrm{Zr}$, starting out again at $\mathrm{Ba}$ and approaching once more as we pass up through $\mathrm{Au}$ to $\mathrm{Pb}$ to Bi. In fig. 9 (Pl. III.) the division into sections is at the $\mathrm{Ba}$, the sub-group having a smaller and smaller speed as we pass up from $A$ s to $S b$, starting out again at $\mathrm{Au}$ and diminishing to $\mathrm{Bi}$. All this is exactly as is required by the photo-electric equation.

Because of the difficulties involved in obtaining experimental curves which will bear differentiation with any

$$
\begin{aligned}
& * \frac{\mathrm{E}}{n_{0} h a^{\frac{1}{2}}}=\frac{\frac{1}{2} m v^{2} a^{\frac{1}{2}}}{n_{0} h v^{2}}=\frac{\frac{1}{2} m a^{\frac{1}{2}}}{n_{0} h}, \text { from } v^{4}=a d . \\
& + \text { Phil. Mag. ser. 6, vol, xxv. p. } 28 \text { (1913). }
\end{aligned}
$$


accuracy, the results of this jart of the work must be taken qualitatively rather than quantitatively.

I desire to express my thanks to Protessor O.W. Richardson for his kind interest in this work.

The ceneral conclusions may be summarized as follows:-

(1) It is improbable that the maximum speed of ejection of electrons from different substances under the influence of X-rays of detinite wave-length is exactly constant independently of the nature of the substance, and dependent only upon the frequency of the incident X-rays. These experiments hare shown that throughout the whole range of motion the distribution of electrons depends fundamentally upon the substance from which they are emitted, but the difference, if any, in the maximum velocities is too small to be demonstrable by this method.

(2) The experimental results point to the conclusion that there may be sperds of emission of electrons from an atom (S) when $\mathrm{X}$-rays of frequency $v$ fall upon it given by eithrer

$$
\frac{1}{2} m v^{2}=h v-{ }_{\mathrm{s}}\left(h v_{\mathrm{K}}+h v_{\mathrm{J}}+h v_{\mathrm{M}}+\ldots\right),
$$

each successive speed being given by the removal of a term from the bracket, commeneing with the term, or

$$
\frac{1}{2} m v^{2}=h v-{ }_{\mathrm{S}}(h v)_{\mathrm{K} \text { or L or } \mathrm{M}},
$$

the expression in brackets representing the potential energy of the electron from whichever atomic ring it was ejected, $v_{\mathrm{K}}, v_{\mathrm{L}}$ etc. being the $\mathrm{K}, \mathrm{L}$, etc. frequencies of the $\mathrm{X}$-ray spectral lines of the parent atom (S). The experimental data agree rather better with the latter expression.

(3) There is a type of electronic emission fundamentally associated with each type of X-ray emission. Assuming. that it is not a necessary condition that each of the radiating atoms of one substance sbould be emitting all possible types of spectral lines, from those of highest eneroy downwards, then the energy of electronic emission of any one of these atoms is complomentary to that of its wave-emission; in other words, the " $\mathrm{K}$ " electron is the slowest on emergence, the concomitant " $L$ " electron faster, and so on. 
SIMONs.

FI⿳艹. 3

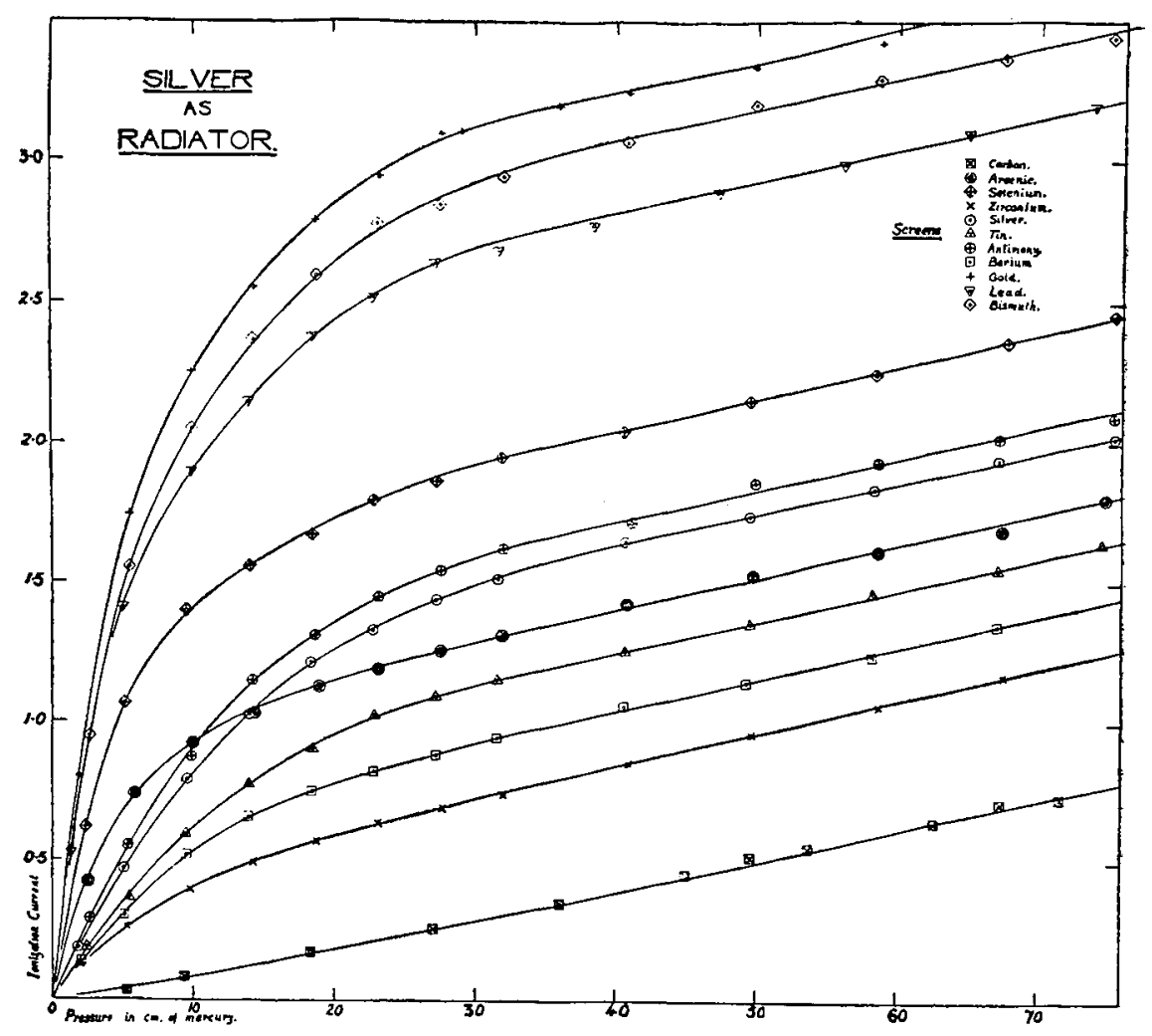

Fig. ̃).

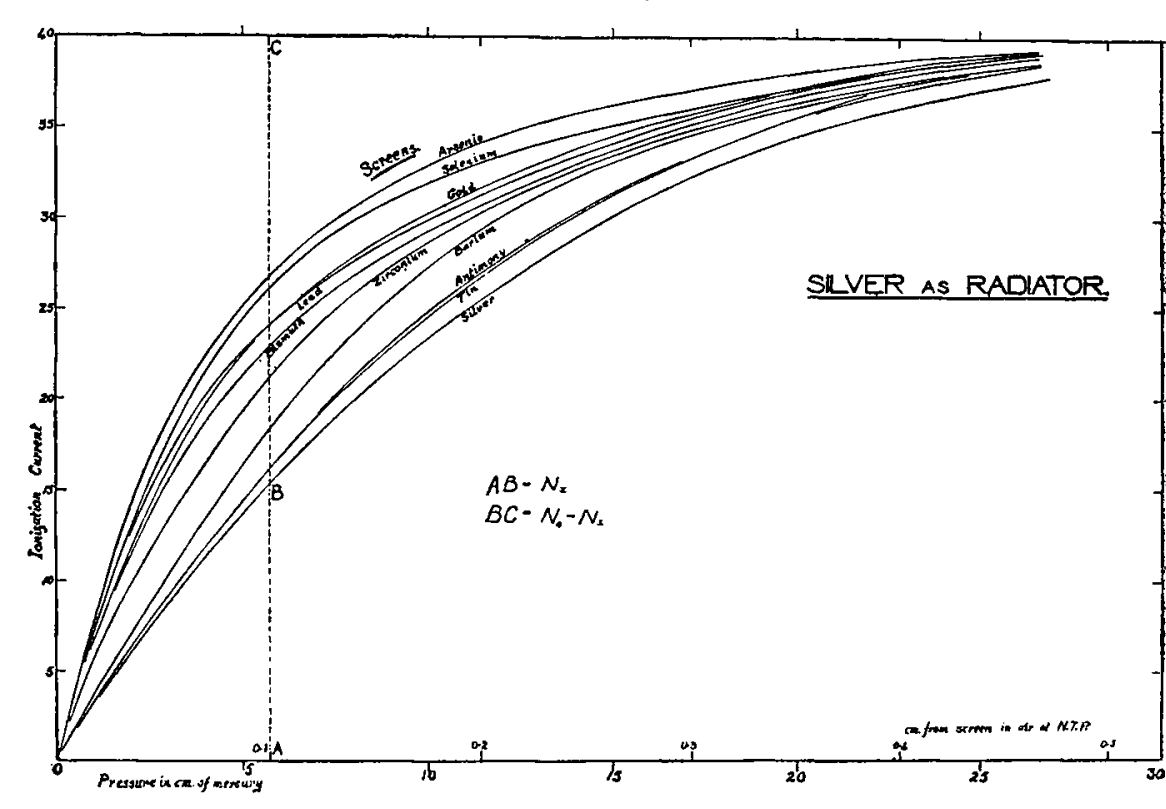

Frg. 7 .

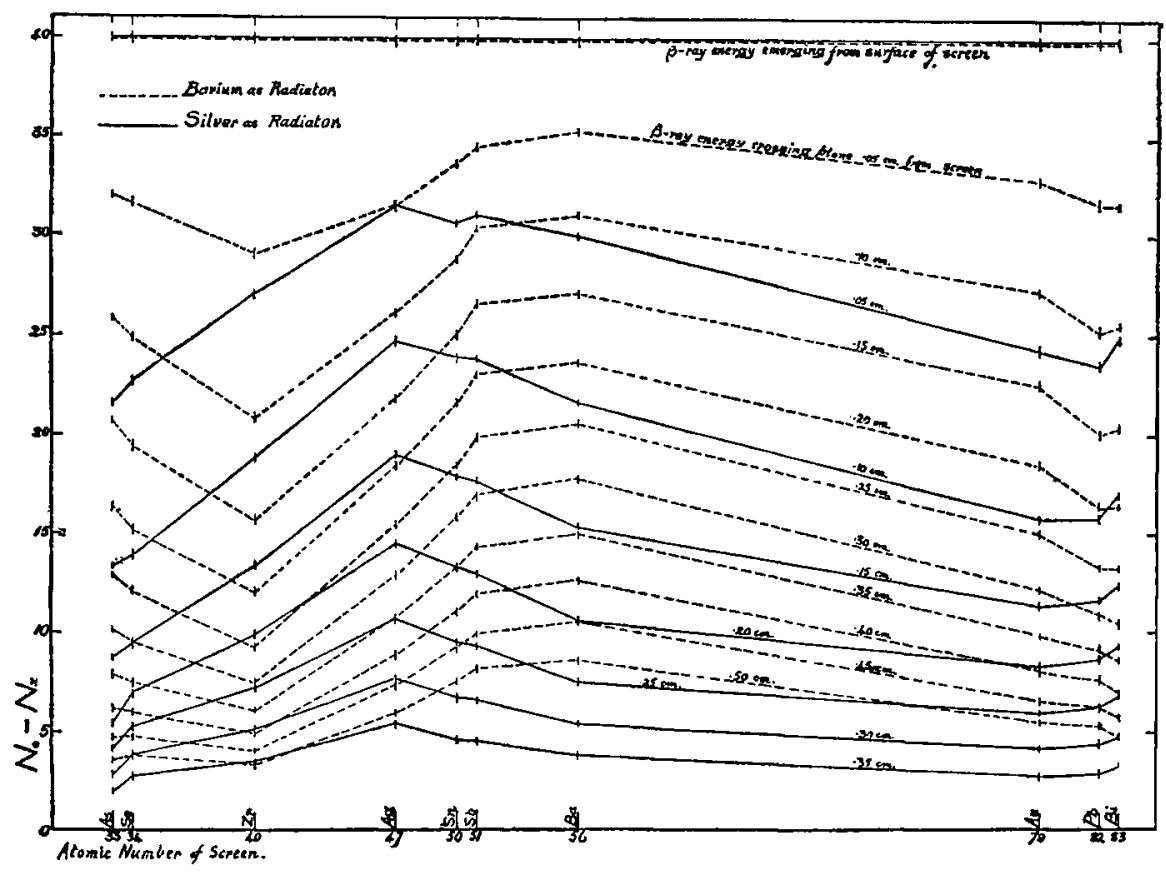

Fra. 7.-Ordinates $\left(\mathrm{N}_{0}-\mathrm{N}_{x}\right)$ proportional to the $\beta$-ray energy crossing imaginary planes in air, at $0^{\circ} \mathrm{C}$. and $76 \mathrm{~cm}$. pressure, at distances from the illumin$\beta$-ray energy to be the same from all the screens.
Phil. Mag. Ser. 6, Vol. 41. PJ. III.
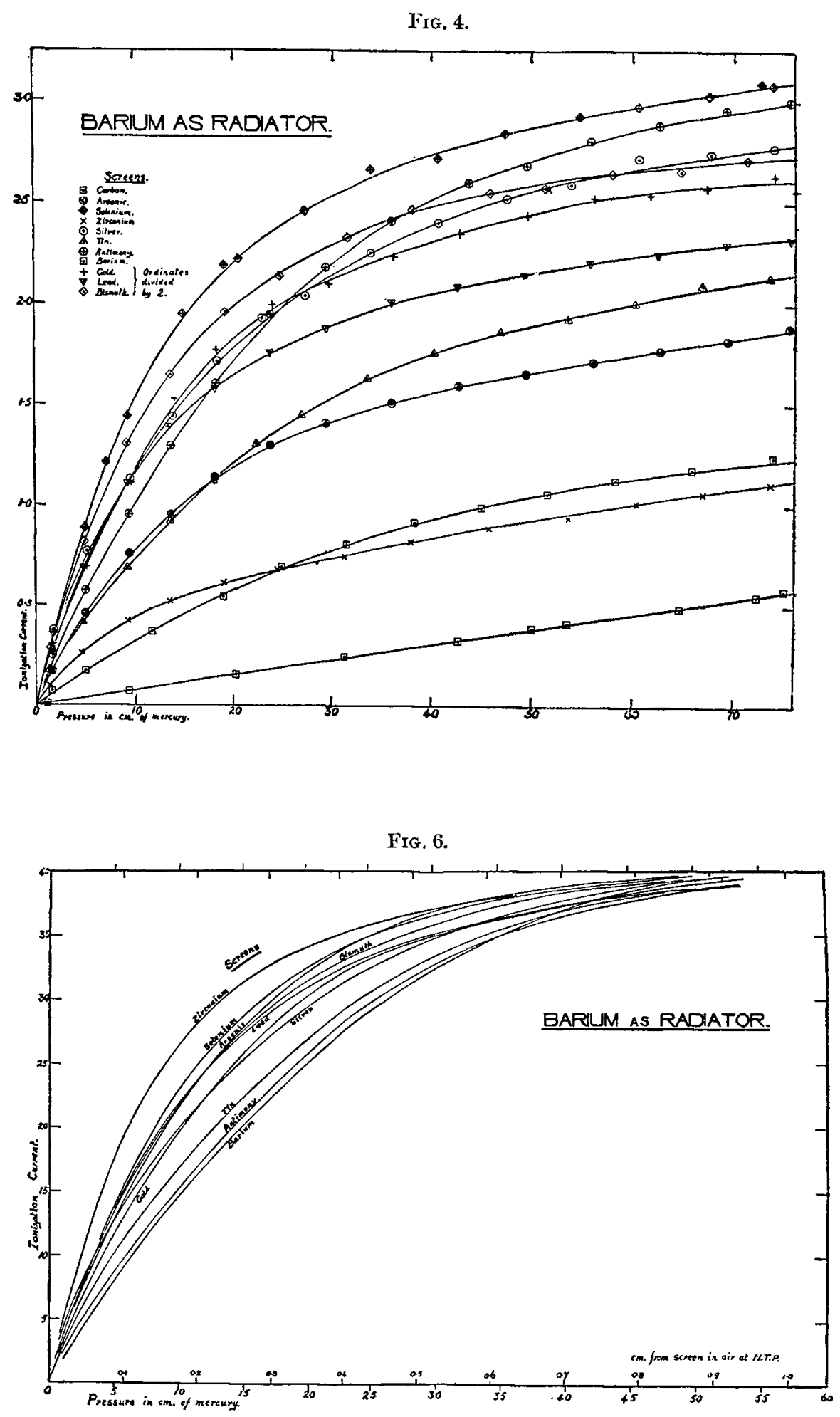

Fra.8.

Fra. 9.

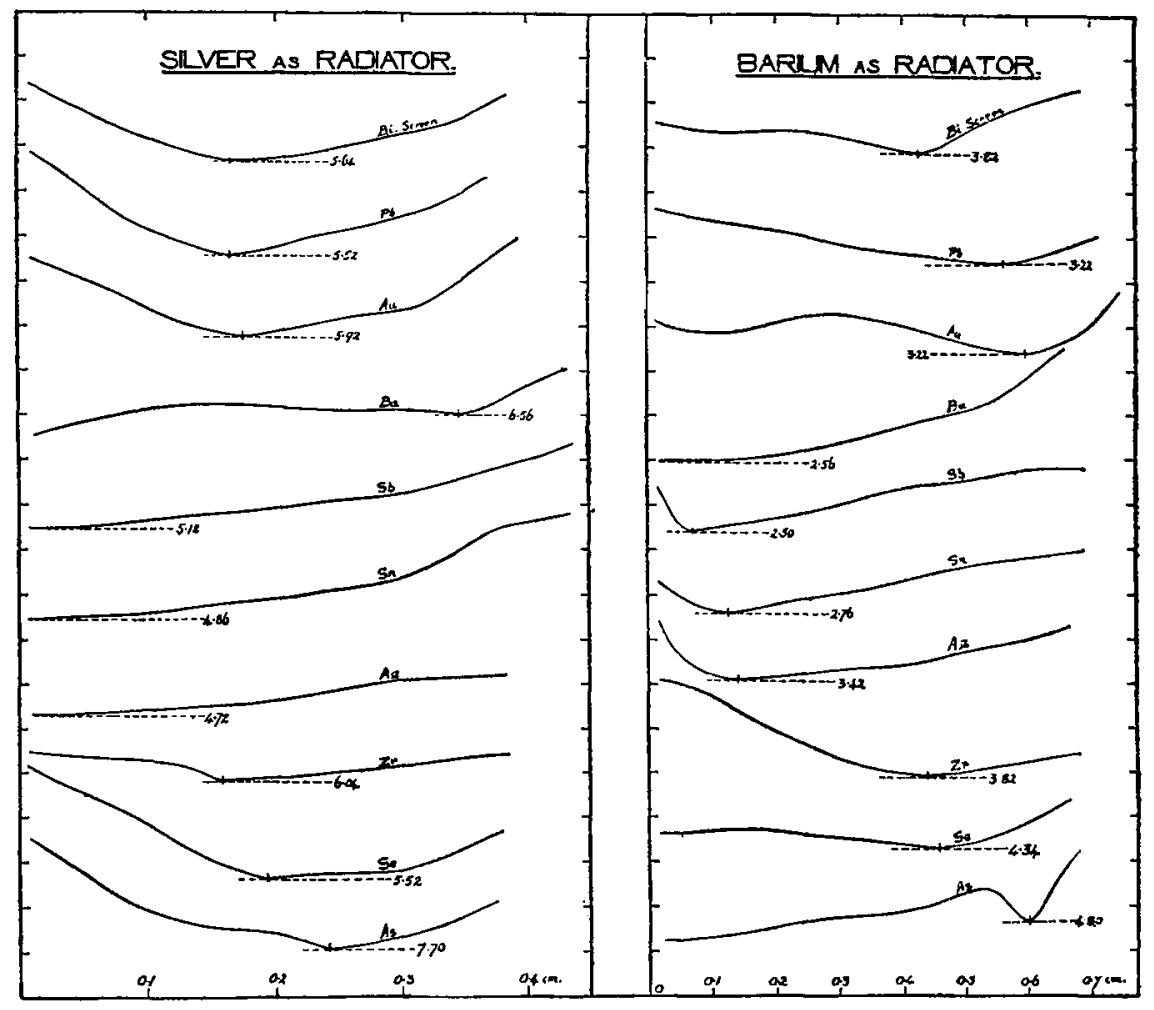

Frgs. 8 \& 9.-For abscissæe, distances from the screen as measured in air at $0^{\circ} \mathrm{C}$. an $76 \mathrm{~cm}$. pressure. For ordinates, $-\frac{d}{d x} \log _{e}\left(\mathrm{~N}_{0}-\mathrm{N}_{x}\right)$, taken from figs. 5 and 6 , each division on fig. 8 representing a change of 2.626 in this function and on fig. 9, 1.313. One absolute value of $-\frac{d}{d x} \log _{e}\left(\mathrm{~N}_{0}-\mathrm{N}_{x}\right)$ is placed on each curve

for reference. the sereens suffers a marked change at the distance indicated. 